\title{
Nonspecific Bacterial Flora Isolated from the Body Surface and Inside Ixodes ricinus Ticks
}

\author{
HUBERT OKŁA*, MALWINA SOSNOWSKA, KRZYSZTOF P. JASIK*, JAN SŁODKI \\ and ROBERT D. WOJTYCZKA
}

\begin{abstract}
Department of Microbiology and Virology, The School of Pharmacy and the Division of Laboratory Medicine in Sosnowiec, Medical University of Silesia in Katowice, Poland
\end{abstract}

Received 30 January 2012, revised 2 March 2012, accepted 12 July 2012

\begin{abstract}
Ixodes ricinus and other representatives of the order Ixodida are vectors of typical pathogens: Borrelia burgdorferi sensu lato, Anaplasma phagocytophilium, Babesia spp., a tick-borne encephalitis virus, and other microorganisms which are important from a medical and veterinary point of view. The presented study focuses on the verification of nonspecific bacterial flora of $I$. ricinus. We analyzed ticks collected in a forest region in Silesia, an industrial district in Poland. Methods of classical microbiology and biochemical assays (API 20 NE test, API Staph test and MICRONAUT System) were used for isolation and identification of microorganisms living on the body surface of I. ricinus and inside ticks. The results show the presence of various bacteria on the surface and inside ticks' bodies. During the study, we isolated Acinetobacter lwoffi, Pseudomonas fluorescens, Aeromonas hydrophila, Achromobacter denitrificans, Alcaligenes faecalis, Stenotrophomonas maltophilia, Pseudomonas oryzihabitans, Micrococcus spp., Kocuria varians, Staphylococcus lentus, Kocuria kristinae, Streptococcus pneumoniae, Rhizobium radiobacter, Staphylococcus xylosus. Majority of the isolated species are non-pathogenic environmental microorganisms, but some of the isolated bacterial strains could cause severe infections.
\end{abstract}

Ke y w or ds: Ixodes ricinus, microbiological diagnostic, nonspecific bacterial flora

\section{Introduction}

Ixodes ricinus, as well as other representatives of the order Ixodida, belongs to mites of great biomedical significance. They are parasites of vertebrates and stay in a humid environment during external nonparasitic periods. Ticks are a potential source of viral, bacterial, and protozoan infections of the hosts. Co-evolution of ticks and microorganisms is the cause of the close, specific and strong connection between vector and the host (Sonenshine, 1993). Because the specificity of the vector-microorganism interaction is so strong, we generally use the term "tick-borne diseases" (TBD) to describe specific diseases transmitted by certain ticks. Typical pathogens transmitted by I. ricinus are Borrelia burgdorferi sensu lato (Stańczak et al., 2000; Paulauskas et al., 2008), Anaplasma phagocytophilum (Stańczak et al., 2004), Babesia spp. (Słodki et al., 2011), and a tick-borne encephalitis virus (Makówka et al., 2009). This does not mean that other microorganisms are excluded, bacterial flora which colonises these mites is abundant and diverse (Stojek et al., 2005; Murrell et al., 2003). From a medical and veterinary point of view, the ability of ticks to carry other non-specific pathogens that may cause additional symptoms occurring after a tick bite, should prompt the analysis of the whole non-specific flora.

The aim of this study was to identify non-specific bacteria transmitted by I. ricinus.

\section{Experimental}

\section{Materials and Methods}

I. ricinus ticks, were collected during a springsummer peak activity of this species in a forest region in Silesia, an industrial district in Poland. Thirty-six adult individuals were collected, among them $75 \%$ were females and $25 \%$ males.

* Corresponding authors: K. Jasik, Department of Microbiology and Virology, The School of Pharmacy and the Division of Laboratory Medicine in Sosnowiec, Medical University of Silesia in Katowice, Jagiellońska 4, 41-200 Sosnowiec, Poland; phone: (+48)323641622; e-mail:kjasik@sum.edu.pl

H. Okła, Department of Microbiology and Virology, The School of Pharmacy and the Division of Laboratory Medicine in Sosnowiec, Medical University of Silesia in Katowice, Jagiellońska 4,41-200 Sosnowiec, Poland; phone: (+48) 323641622; e-mail: hubert.okla@gmail.com 
Bacteriological diagnostics. Bacterial flora living on the surface and inside their bodies was isolated from the collected ticks. In order to isolate bacteria from the tick's surface, the ticks were washed in sterile physiological saline solution. Then $100 \mu \mathrm{l}$ of the solution was transferred to nutrient agar (BTL, Łódź, Poland) to multiply bacteria which were later plated on blood agar plates. The plates were incubated for $48 \mathrm{~h}$ at $37^{\circ} \mathrm{C}$ in aerobic conditions.

To isolate bacteria from inside of the ticks, ticks were washed first in $1 \mathrm{ml}$ of $96 \%$ ethanol to kill bacteria present on the surface. Then the ticks were transferred to physiological saline solution and were mechanically disrupted. Then $100 \mu$ lof the solution was transferred to nutrient agar (BTL, Łódź, Poland) to multiply bacteria which were later plated on blood agar plates. The plates were incubated for $48 \mathrm{~h}$ at $37^{\circ} \mathrm{C}$ in aerobic conditions.

After 48-hours of incubation on blood agar plates, the morphological properties of bacterial colonies were assayed and the following characteristics were recorded: shape, size, surface structure, protruding above the surface, colour, transparency, texture, type of hemolysis. Based on morphological differences of colonies, we isolated pure cultures.

We assayed Gram type and if Gram-negative rods were observed on stained microscopic slide, we plated bacteria on selective media: Mac Conkey Agar (BTL, Łódź, Poland), Cetrimide Agar (BTL, Łódź, Poland), King B Agar (BTL, Łódź, Poland). In case of Grampositive cocci we tested for the presence of catalase and the bacteria were plated on the Chapman Agar (BTL, Łódź, Poland). All cultures were incubated for 24 hours at $37^{\circ} \mathrm{C}$ in aerobic conditions.

Biochemical studies. To identify species isolated from ticks, the API 20 NE and API Staph tests (BioMérieux, Marcy l'Etoile, France) were used according to the instructions supplied by the manufacturer. The results were decoded using the software "apiweb" available on the website of the manufacturer (https://apiweb. biomerieux.com).

Bacterial strains identified neither by classical microbiology methods nor using the API $20 \mathrm{NE}$ and API Staph were analysed by a semi-automatic MICRONAUT System for identification and resistance testing of bacteria and yeasts (Merlin Diagnostika GmbH, BornheimHersel, Germany). The material for analyses was prepared according to the manufacturer's insrtuctions.

\section{Results}

Among thirty-six tested ticks, mesophilic microorganisms were found only in 30 samples. In six bacterial samples, bacterial flora was detected either on the surface or inside of the tick. Microorganisms were more

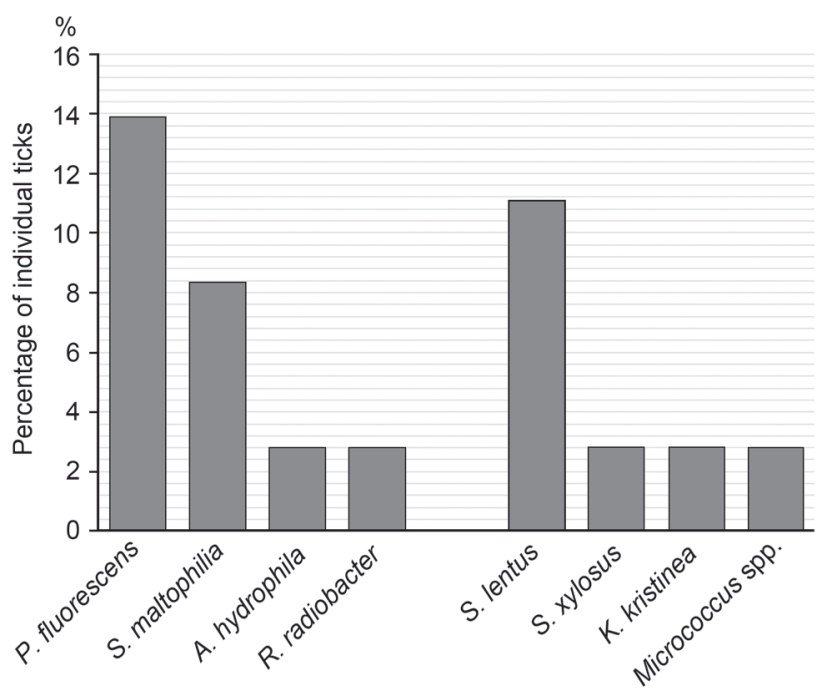

Fig. 1. Bacterial flora on the body surface of I. ricinus

frequently isolated from the body surface of the ticks. The bacteria living on the surface of the ticks' bodies are largely aerobic microorganisms or facultative aerobes. The flora living inside of the body consisted mainly of anaerobes and facultative anaerobic microorganisms, and aerobic microorganisms occurred rarely.

Classical microbiology methods allowed detection of ten strains of Gram-negative rods and twenty-nine strains of Gram-positive cocci living on the surface of the analysed ticks. Using classical methods, we were able to identify few species present on the surface, Pseudomonas fluorescens (14\%, Fig. 1.), Aeromonas hydrophila, Rhizobium radiobacter occurred most frequently among the Gram-negative rods, Stenotrophomonas maltophilia isolates were identified using automated MICRONAUT system.

Among the cocci, the following species were detected: Staphylococcus lentus (11\%, Fig. 1), Staphylococcus xylosus, Kocuria kristinea, and Micrococcus sp.

From the inside of tics we isolated P. fluorescens, A. hydrophila, Achromobacter denitrificans, Alcaligenes faecalis, S. maltophilia, Acinetobacter lwoffii and Pseudomonas oryzihabitans.

Among the Gram-positive cocci living inside the ticks, there were detected the same species of microorganisms as on the body surface: S. lentus, S. xylosus, K. kristinea, Kocuria varians and the cocci of the genus Micrococcus, and Streptococcus pneumoniae.

The most commonly identified rods living inside the ticks were: A. lwoffii (11\%), P. fluorescens (8\%) and S. maltophilia (8\%), while among the cocci S. lentus (11\%) species were the most frequent (Fig. 2).

The identification of isolated bacterial strains showed that the greatest diversity of bacterial flora was present on the surface and inside the bodies of female ticks. Eight species of Gram-negative rods and five species of Gram-positive cocci were isolated from female ticks 


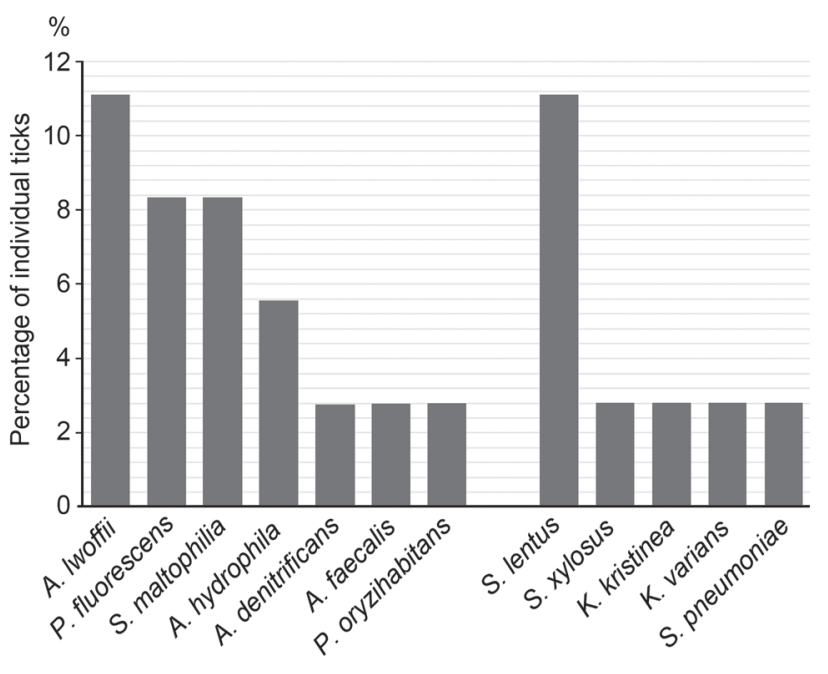

Fig. 2. Bacterial flora inside I. ricinus

(Table I). In male ticks, we observed much lower diversity of bacterial flora on the surface and inside their bodies. Two species of Gram-negative rods and two species of Gram-positive cocci were identified (Table I).

\section{Discussion}

A lot has been published about health problems associated with the transfer of typical tick-related pathogens. However, researchers pay less attention to microorganisms which are nonspecific for ticks. It can be assumed that bacteria transmitted by ticks are mainly nonpathogenic environmental microbes. Nevertheless, the representatives of I. ricinus species have contact with different hosts, thus analysing potential transmission of various microorganisms by these mites is very important.

Earlier publications about the colonisation of I. ricinus by microorganisms identified the presence of various bacteria on the body surface of the ticks, including Pasteurella pneumotropica/haemolytica, Pantoea agglomerans, Serratia marcescens, Serratia plymuthica, Aeromonas hydrophila, Burkholderia cepacia, Chromobacterium violaceum, Pseudomonas aeruginosa and Stenotrophomonas maltophilia (Stojek and Dutkiewicz, 2004). Furthermore, the possibility of transmission of Salmonella enteritidis, Listeria monocytogenes, Erysipelothrix rhusiopathiae by I. ricinus was described (Siuda, 1991). Rahman and Rahman (1980) discovered the presence of Escherichia, Proteus, Pseudomonas and Staphylococcus species in Rhipicephalus sanguineus and Haemaphysalis leachi leachi ticks. In these species of ticks, horizontal transmission of Staphylococcus aureus and Staphylococcus epidermidis was also described (Adejinmi and Ayinmode, 2008.). Studies on the presence of Gram-negative bacteria in hard and soft ticks, Hyalomma dromedarii, Serratia liquefaciens, Stenotrophomonas maltophilia, Klebsiella ornithinolytica and Aeromonas hydrophila were identified. Five species were isolated from Argas persicus: Rahnella aquatilis, Pseudomonas fluorescens, Enterobacter cloacae, Chryseomonas luteola and Chryseobacterium meningosepticum (Montasser, 2005). Also fungi were identified as important elements of the flora on the surface and inside ticks; Scopulariopsis brevicaulis was isolated from Dermacentor variabilis ticks (Yoder et al., 2003), Penicillium spp, Fusarium spp, and S. brevicaulis were found on the body surface of I. ricinus, D. reticulatus and D. marginatus (Samsinakova et al., 1974).

Published research suggests differences between the microflora associated with different species of ticks which live in various environments (Murrell et al., 2003; Martin and Schmidtmann, 1998; Amoo et al., 1987). However, it does not mean that isolated microorganisms are potentially pathogenic and may influence a clinical presentation after a tick bite or tick contact with injured skin. It is more noticeable that some species of bacteria are repeatedly observed in ticks. Comparison of literature data with our results shows that Pseudomonas fluorescens, Stenotrophomonas maltophilia and Aeromonas hydrophyte are isolated from ticks in different regions of the world. Previously, the occurrence of bacteria such as: S. lentus, S. xylosus $R$. radiobacter, K. kristinae, A. denitrificans, A. faecalis, P. oryzihabitans, K. varians, S. pneumoniae, A. lwoffii in the I. ricinus ticks was not observed.

In our studies, S. lentus, A. lwoffii, S. maltophilia and $P$. fluorescens were isolated most frequently, and association of these species with ticks may have epidemiological and medical consequences. Generally, S. lentus is

Table I

Bacterial flora of male and female I. ricinus ticks

\begin{tabular}{|c|c|c|c|}
\hline $\begin{array}{l}\text { Sex of } \text { I. ricinus } \\
\text { ticks }\end{array}$ & $\begin{array}{l}\text { Area of the } \\
\text { ticks' body }\end{array}$ & Rods & Cocci \\
\hline \multirow[t]{2}{*}{ Males } & surface & P. fluorescens & S. lentus, S. xylosus \\
\hline & inside & S. maltophilia & S. lentus \\
\hline \multirow[t]{2}{*}{ Females } & surface & P. fluorescens, A. hydrophila, R. radiobacter, S. maltophilia & Micrococcus spp., S. lentus, K. kristinae \\
\hline & inside & $\begin{array}{l}\text { A. lwoffii, P. fluorescens, A. hydrophila, A. denitrificans, } \\
\text { A. faecalis, S. maltophilia, P. oryzihabitans }\end{array}$ & $\begin{array}{l}\text { Micrococcus spp., K. varians, S. lentus, } \\
\text { K. kristinae, S. pneumoniae }\end{array}$ \\
\hline
\end{tabular}


described as a non-pathogenic species. However, it is sometimes isolated from patients with urinary tract infections (Stepanović et al., 2003; Stepanović et al., 2005). Moreover, Nawrotek et al. (2010) isolated coagulase-negative staphylococci (CNS) such as S.lentus and S. xylosus from the milk of cows with symptoms of the mammary gland inflammation (mastitis). There are genes encoding enterotoxins in the genome of these staphylococci, and as a consequence, S. lentus and S. xylosus can potentially cause enterotoxin poisoning in people who have consumed milk and dairy products. At the same time, the occurrence of these staphylococci in ticks creates the opportunity of spreading virulent bacteria that produce toxins among cattle.

Acinetobacter lwoffii and S. maltophilia may have clinical relevance in the case of infections in patients with lower immunity. A. lwoffii are Gram-negative rods constituting the physiological flora of human skin. However, these bacteria are dangerous for hospitalised patients (Ku et al., 2000). These rods show tropism toward the mucous membrane of urinary tract and often are multidrug resistant (Tega et al., 2007). A. lwoffii seems to be more pathogenic for animals, e.g. birds, causing severe respiratory diseases (Robino et al., 2005). There was also a case of fulminant communityacquired pneumonia in humans, probably caused by A. lwoffii with fatal outcomes (Toyoshima et al., 2010). Such infections show that the pathogenesis and transmission of $A$. lwoffii requires further study, and the presence of these bacteria in ticks infesting animals and humans cannot be ignored. S. maltophilia and Acinetobacter spp. are widespread in environment. Their medical significance is mainly limited to the hospital environment, because these rods cause nosocomial infections such as injured skin infections and soft tissue infections, pneumonia, meningitis, endocarditis and urinary tract infections. (Araoka et al., 2010). Patients with cystic fibrosis show an increased risk of infection by S. maltophilia (Colin and Rabin, 2011). Although the frequency of S. maltophilia infections is not high, these cases pose serious problems because the risk of death arising from these infections is estimated at 20-70\% (Farrell et al., 2010). Moreover, S. maltophilia rods have natural resistance mechanisms and therefore they may have greater medical significance. These rods are not only responsible for the pathogenesis of diseases difficult to treat, but they are a source of drug resistance genes for other bacteria. Researches described the possibility to transfer resistance genes from strains of S. maltophilia to other non-fermenting rods such as P. aeruginosa and the other Enterobacteriaceae (Izydorczak and Stefańska, 2007). Thus, every way of spreading of S. maltophilia, including infection by ticks, may have clinical relevance, especially in the case of co-infection with typical ticks pathogens.
Non-fermenting rods P.fluorescens constituted a quite large percentage of isolated bacteria in our studies. However, they have no clinical significance outside the hospital environment. They are isolated very rarely in immunocompromised patients. It is believed that some strains of P. fluorescens may be of great importance for intestinal inflammation (Madi et al., 2010).

The number of other isolated bacteria did not exceed $3 \%$. Some are potentially pathogenic species such as S. pneumoniae and A. hydrophila (Jacobs, 2007; Saidi et al., 2011). However, the majority of them are mostly opportunistic pathogens that infect immunocompromised patients. Group of opportunistic pathogens isolated in our study consists of S. xylosus, R. radiobacter, K. kristinae, A. faecalis, P. oryzihabitans, A. denitrificans (Orrett and Shurland, 1998; Sood et al., 2010; Martinaud et al., 2008; Freney et al., 1988; Mensah et al., 1989).

\section{Literature}

Adejinmi J.O. and A.B. Ayinmode. 2008. Transmission of bacteria isolates through all the developmental stages of dog ticks (Bacteriological evidence). J. Anim. Vet. Adv. 7: 959-962.

Amoo A.O., O.O. Dipeolu, A.O. Akinboade and A. Adeyemi. 1987. Bacterial isolation from and transmission by Boophilus decoloratus and Boophilus geigyi. Folia Parasitol. 34: 69-74.

Araoka H., M. Baba and A. Yoneyama. 2010. A risk factors for mortality among patients with Stenotrophomonas maltophilia bacteremia in Tokyo, Japan, 1996-2009. Eur. J. Clin. Microbiol. Infect. Dis. 29: 605-608.

Colin A.A and H.R. Rabin. 2011. Stenotrophomonas maltophilia in cystic fibrosis: guilty or innocent? Am. J. Respir. Crit. Care. Med. 183: 564-566.

Farrell D.J., H.S. Sader and R.N. Jones. 2010. Antimicrobial susceptibilities of a worldwide collection of Stenotrophomonas maltophilia isolates tested against tigecycline and agents commonly used for S. maltophilia infections. Antimicrob. Agents Chemother. 54: 2735-2737.

Freney J., W. Hansen, J. Etienne, F. Vandenesch and J. Fleurette. 1988. Postoperative infant septicemia caused by Pseudomonas luteola (CDC Group Ve-1) and Pseudomonas oryzihabitans (CDC Group Ve-2). J. Clin. Microbiol. 26: 1241-1243.

Izydorczak M. and J. Stefańska. 2007. Antimicrobial agent triclosan-activity, applications and hazards (in Polish). Biul. Wydz. Farm. 2: $13-17$.

Jacobs M.R. 2007. Clinical significance of antimicrobial resistance in S. pneumoniae. SAMJ, 97: 1133-1140.

Ku S.C., P.R. Hsueh, P.C. Yang and K.T. Luh. 2000. Clinical and microbiological characteristics of bacteremia caused by Acinetobacter lwoffii. Eur. J. Clin. Microbiol. Infect. Dis. 19: 501-505.

Madi A., P. Svinareff, N. Orange, M.G.J. Feuilloley and N. Connil. 2010. Pseudomonas fluorescens alters epithelial permeability and translocates across Caco-2/TC7 intestinal cells. Gut. Pathogens. 2: 16. Makówka A., W. Gut and P. Stefanoff. 2009. Detection of TBEV RNA in ticks as a tool for valuation of endemic area and sensitivity of TBE surveillance (in Polish). Przegl. Epidemiol. 63: 377-380. Martin P.A.W. and E.T. Schmidtmann. 1998. Isolation of aerobic microbes from Ixodes scapularis (Acari: Ixodidae), the vector of Lyme disease in the eastern United States. J. Econ. Entomol. 91: 864-868. Martinaud C., T. Gaillard, P. Brisou, O. Gisserot and J.P. de Jaureguiberry. 2008. Bacteremia caused by Kocuria kristinae in a patient with acute leukemia. Med. Mal. Infect. 38: 165-166. 
Mensah K., A. Philippon, C. Richard and P.A.D. Grimont. 1989. Infections nosocomiales a Alcaligenes denitrificans subsp. xylosoxidans: Sensibilite de 41 souches a 38 antibiotiques. Médecine et Maladies Infectieuses. 19: 167-172.

Montasser A.A. 2005. Gram-negative bacteria from the camel tick Hyalomma dromedarii (Ixodidae) and the chicken tick Argas persicus (Argasidae) and their antibiotic sensitivities. J. Egypt. Soc. Parasitol. 35: 95-106.

Murrell A., S.J. Dobson, X. Yang, E. Lacey and S.C. Barker. 2003. A survey of bacterial diversity in ticks, lice and fleas from Australia. Parasitol. Res. 89: 326-334.

Nawrotek P, M. Świderska, K. Fijałkowski, K. Kogut and D. Czernomysy-Furowicz. 2010. Detection of enterotoxigenic Staphylococcus spp. strains, isolated from cows with mastitis, using multiplex-PCR. Acta. Sci. Pol. Zootechnica, 9: 161-172.

Orrett F.A. and S.M. Shurland. 1998. Significance of coagulasenegative staphylococci in urinary tract infections in a developing country. Conn. Med. 62:199-203.

Paulauskas A., D. Ambrasiene, J. Radzijevskaja, O. Rosef and J. Turcinaviciene. 2008. Diversity in prevalence and genospecies of Borrelia burgdorferi sensu lato in Ixodes ricinus ticks and rodents in Lithuania and Norway. Int. J. Med. Microbiol. 298: 180-187.

Rahman M.H. and M.M. Rahman. 1980. Occurrence of some bacterial isolates in ticks found in Madhpur Forest Area. Bangladesh Vet. J. 14: 43-47.

Robino P., E. Bert, C. Tramuta, S. Ceruti Sola and P. Nebbia. 2005. Isolation of Acinetobacter lwoffii from a lovebird (Agapornis roseicollis) with severe respiratory symptoms. Schweiz. Arch. Tierheilkd. 147: 267-269.

Saidi N., M. Snoussi, D. Usai, S. Zanetti and A. Bakhrouf. 2011. Adhesive properties of Aeromonas hydrophila strains isolated from Tunisian aquatic biotopes. Afr. J. Microbiol. Res. 5: 5644-5655.

Samsinakova A., S. Kalalova, M. Daniel, F. Dusbabek, E. Honzakova and V. Cerny. 1974. Entomogenous fungi associated with the tick Ixodes ricinus (L.). Folia Parasitol. 21: 39-48.

Siuda K. 1991. Ticks (Acari: Ixodida) of Poland. Part I. General Problems. PWN. Warszawa (in Polish).

Słodki J., K.P. Jasik, M. Kępa, D. Idzik and R.D. Wojtyczka. 2011. Tick-transmitted diseases caused by apicomplexa. Acta Protozool. 50: $155-161$.
Sonenshine D.E. (ed.) 1993. Biology of ticks. Vol. 2. Oxford University Press, New York.

Sood S., Nerurkar V. and S. Malvankar. 2010. Catheter associated bloodstream infection caused by $R$. radiobacter. Ind. J. Med. Microbiol. 28: 62-64.

Stańczak J., B. Kubica-Biernat, M. Racewicz, W. KruminisLozowska and W. Kur. 2000. Detection of three genospecies of Borrelia burgdorferi sensu lato in Ixodes ricinus ticks collected from different regions of Poland, Int. J. Med. Microbiol. 290: 559-566.

Stańczak J., R.M. Gabre, W. Kruminis-Łozowska, M. Racewicz and B. Kubica-Biernat. 2004. Ixodes ricinus as a vector of Borrelia burgdorferi sensu lato, Anaplasma phagocytophilum and Babesia microti in urban and suburban forests. Ann. Agric. Environ. Med. 11:109-114.

Stepanović S., I. Dakić, D. Morrison, T. Hauschild, P. Ježek, P. Petráš, A. Martel, D. Vuković, A. Shittu and L.A. Devriese. 2005. Identification and characterization of clinical isolates of members of the Staphylococcus sciuri group. J. Clin. Microbiol. 43: 956-958.

Stepanović S., P. Ježek, D. Vuković, I. Dakić and P. Petráš. 2003. Isolation of members of the Staphylococcus sciuri group from urine and their relationship to urinary tract infections. J. Clin. Microbiol. 41: 5262-5264.

Stojek N.M. and J. Dutkiewicz. 2004. Studies on the occurrence of gram-negative bacteria in ticks: Ixodes ricinus as a potential vector of Pasteurella. Ann. Agric. Environ. Med. 11: 319-322.

Stojek N.M., J. Dutkiewicz, and J. Polak. 2005. Gram-negative rods isolated from the surface of Ixodes ricinus (L.) (Acari: Ixodida: Ixodidae) ticks. In: Buczek A. and Cz. Błaszak (eds.) Arthropods. A variety of forms and interactions. Koliber, Lublin.

Tega L., K. Raieta, D. Ottaviani, G.L. Russo, G. Blanco and A. Carraturo. 2007. Catheter-related bacteremia and multidrug-resistant Acinetobacter lwoffii. Emerging Infectious Diseases, 13: 355-356. Toyoshima M., K. Chida and T. Suda. 2010. Fulminant community-acquired pneumonia probably caused by Acinetobacter lwoffii. Respirology, 15: 867-868.

Yoder J.A., P.E. Hanson, L.W. Zettler, J.B. Benoit, F. Ghisays and K.A. Piskin. 2003. Internal and external mycoflora of the american dog tick, Dermacentor variabilis (Acari: Ixodidae), and its ecological implications. Appl. Environ. Microbiol. 69: 4994-4996. 